\title{
O poder do lixo: abordagens antropológicas dos resíduos sólidos
}

\section{Claudia Ambrosi ${ }^{1}$}

https://orcid.org/0000-0002-6943-0557

${ }^{1}$ Universidade Federal de Santa Catarina, Centro de Filosofia e Ciências Humanas, Programa de Pós-Graduação Interdisciplinar em Ciências Humanas, Florianópolis, SC, Brasil

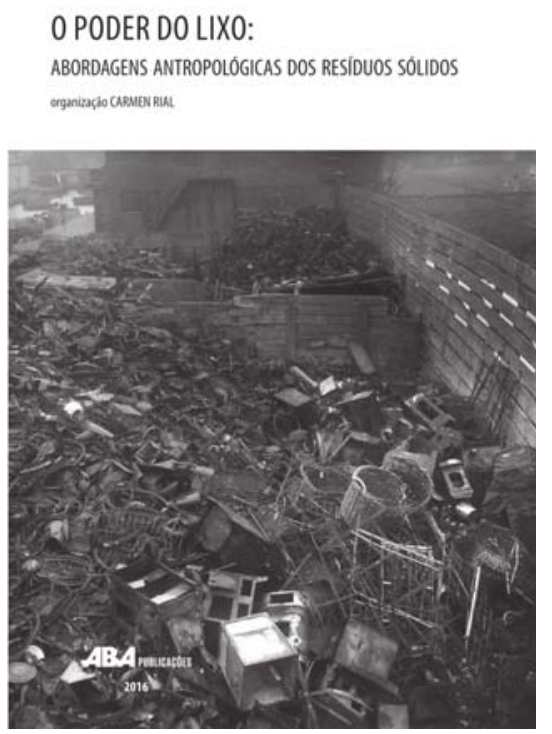

RESENHA: O poder do lixo: abordagens antropológicas dos resíduos sólidos

RIAL, Carmen (org.). O poder do lixo: abordagens antropológicas dos resíduos sólidos. Rio de Janeiro: Associação Brasileira de Antropologia, 2016. $432 \mathrm{p}$.

REVIEW: The power of waste: Anthropological approaches to solid waste

RIAL, Carmen (org.). O poder do lixo: abordagens antropológicas dos resíduos sólidos [The power of waste: anthropological approaches to solid waste]. Rio de Janeiro: Associação Brasileira de Antropologia, 2016. 432 p.

Recebido em 01.10.2018. Aprovado em 20.11.2018. Revisado em 29.05.2019.

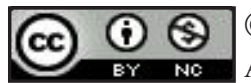

(C) O(s) Autor(es). 2019 Acesso Aberto Esta obra está licenciada sob os termos da Licença Creative Commons Atribuição-NãoComercial 4.0 Internacional (https://creativecommons.org/licenses/by-nc/4.0/deed.pt_BR), que permite copiar, distribuir e reproduzir em qualquer meio, bem como adaptar, transformar e criar a partir deste material, desde que para fins não comerciais e que você forneça o devido crédito aos autores e a fonte, insira um link para a Licença Creative Commons e indique se mudanças foram feitas. 
A obra $O$ Poder do Lixo: abordagens antropológicas dos resíduos sólidos, publicada no Brasil pela Associação Brasileira de Antropologia (ABA), disponível na versão eletrônica ${ }^{1}$, é uma coletânea que abrange muitas questões importantes e atuais sobre o potencial revelador do que é chamado lixo, fundamentalmente em dois países com realidades distintas: Brasil e Holanda. O primeiro, caracterizado pela sua ampla extensão territorial e populacional, economia emergente e conhecido por sua desigualdade social; enquanto o segundo, com pequenas dimensões geográficas, conhecido por sua história e política de um Estado de bem-estar social.

Carmem Rial, organizadora do livro, oferece um olhar comparativo entre os dois países a partir da concentração no tema, principalmente de uma abordagem antropológica social e cultural e também interdisciplinar, o que pode ser observado nos perfis dos autores. Alguns dos capítulos são escritos por holandeses que visitaram o Brasil, enquanto outros são escritos por brasileiros que pesquisaram na Holanda. A obra está dividida em três grandes tópicos contendo treze textos heterogêneos, de conteúdo que se encaixa na temática acerca aos conflitos sociais, ideologia e cultura. Adicionalmente, traz uma abordagem acerca dos novos lixos e seus riscos para a sociedade, a partir da contextualização de descarte consciente.

A principal contribuição da publicação foi agrupar os estudos em quatro abordagens da antropologia, a saber: 1) o enfoque simbólico, como as pessoas veem o lixo (olhos do observador é que definem) e que ele não é um objeto, mas uma categoria socialmente construída; 2) a ecologia política, tem base principalmente nas relações de poder, nas desigualdades e na visibilidade, que faz o lixo parecer mais sujo em áreas ocupadas por grupos estigmatizados; 3 ) a abordagem crítica, especialmente ao consumismo conspícuo que gera desperdício evidente, o qual pode ser uma forma de evitar colapso do capitalismo. O estudo mostra que a arte realizada a partir dos materiais descartados é uma das formas de reinvenção de consumo; e 4) a perspectiva holística, pode ser concebida a partir dos exemplos (casos citados), e que direcionam o foco para atuação dos atores e seus modos de vida, como diz o ditado: o lixo de uns é o tesouro de outros, e isso consistiria em um processo de purificação, em que é necessária a participação da sociedade a partir das diferentes motivações dos indivíduos.

A presente resenha foi dimensionada de forma a apresentar os textos agrupados de acordo com as quatro abordagens da antropologia descritas acima, e que estão divididos dentre as três grandes seções do livro, descritas a seguir. No primeiro capítulo, denominado Catadores, os heróis da reciclagem, dos autores Freek Colombijn e Martina Morbidini, é mencionada a importante citação de Medina (2010, p. 58 apud RIAL, 2016, p. 43), de que "a formação de cooperativas de catadores pode resultar em desenvolvimento de base, redução da pobreza e proteção ambiental". Embora os autores também sinalizem os prós e contras dessa formação, fazendo uma comparação entre o Brasil e a Indonésia. Para tal, fazem alusão ao que chamaram de braço protetor (cooperativa) ou a mão invisível (liberdade). Aqui no Brasil, os catadores de resíduos encontram as duas opções, mas ressaltam que, a partir dos achados no estudo comparativo, infelizmente, verificaram que os trabalhadores da Indonésia não dispõem dessa opção de escolha.

A holandesa Martina Morbidini pesquisou elementos de mobilização social e investigou o trabalho digno dos catadores de material reciclável, em sua experiência na cidade de Belo Horizonte, Brasil. O foco dela foi analisar conflitos e desafios em espaços e culturas urbanas. Estratégias observadas nesse capítulo, utilizam discursos sustentáveis sobre prática da reciclagem, que pode ajudar o percurso de inclusão socioeconômica dos catadores. Isso deveria ser comunicado aos cidadãos urbanos através do discurso ambientalista e da arte.

Convém observar que a temática dos catadores e da arte é abordada de forma sensacional também no cinema nacional, e cito aqui o exemplo da comunidade de catadores que saiu do opróbio social em que viviam a partir da iniciativa de transformar lixo em obras de arte. Trata-se do documentário Lixo Extraordinário, um filme de Lucy Walker (2010 apud RIAL, 2016), idealizado e protagonizado pelo artista plástico Vic Muniz².

O poder de transformação que a arte tem sobre a existência cotidiana e sobre a sociedade é amplamente argumentado no capítulo de Andrea Eichenberger. A partir de seu relato de experiências e registro de imagens, proporciona um olhar instigante à estética do lixo. Quando o lixo é problematizado, é então possível construir um diálogo social e colaborativo. O texto revela que em Amsterdã, apesar das políticas envolvendo separação e destino adequado de resíduos, o abandono de objetos em locais inapropriados é muito evidente. Expõe notória falta de separação de resíduos dentro do restaurante da universidade, onde os atores são a própria comunidade estudantil. Porém, apesar da percepção do lixo como presença onipotente na sociedade atual, a partir da visão artística, a autora parafraseia Paul Ardenne (2003 apud RIAL, 2016, p. 249), o qual descreveu "[...] que este mundo, por mais fracassado que esteja, não está perdido".

Entrando no segundo tópico, intitulado Reciclagem, Reaproveitamento e Estilo de Vida, os autores brasileiros relatam suas experiências na Holanda e vice-versa: além de evidenciarem os fortes contrastes apresentados em dados, nas formas de como os países tratam a produção e a destinação dos resíduos sólidos, ainda perfazem uma rica narrativa com base na visão dos imigrantes brasileiros vivendo na Holanda. $\mathrm{O}$ texto de Viviane Kraieski de Assunção levanta questões sobre o país do desperdício, apresentando dados que são 
um verdadeiro choque de realidades, onde apenas 4\% de Resíduos Sólidos (RS) são depositados em aterros sanitários na Holanda, contrastando com os dados brasileiros, onde mais de 2/3 dos RS recebe uma destinação inadequada sob o ponto de vista ecológico. Cabe destacar que no Brasil a preocupação ambiental e a tomada de medidas governamentais como a Política Nacional de Resíduos Sólidos (PNRS) (BRASIL, 2010 apud RIAL, 2016) vêm sendo instituídas somente 40 anos após a regulamentação de leis similares na Holanda. Além de iniciativa tardia, muitas vezes não é implantada completamente.

Mudando o foco da produção para o consumo de lixo, Carmen Rial apresenta a visão do reaproveitamento de materiais descartados e de autoconstrução $0^{3}$ no ethos ecologista, por intermédio do desafio: construir uma trenchtown nos anos 80, na cidade de Florianópolis. Esse termo foi utilizado para definir a casa de pobre acabamento estético, e faz alusão ao bairro da Jamaica onde nasceu o reggae. Cinco casas nasceram da partilha de trabalho e ajuda mútua, sem projeto arquitetônico e construídas utilizando materiais rústicos, numa temática circular em oposição à compartimentalização. A proposta era que elas pudessem se revelar por inteiro ao primeiro olhar, teriam apenas objetos artesanais e outros que remetessem ao meio rural. Grande parte dos materiais foi obtida a partir do comércio de material de demolição, oriundos do desmanche de prédios e casas coloniais do centro histórico desta capital. A busca dos materiais em depósitos se transformou numa "[...] tarefa arqueológica [...] (p. 148), a qual muitas vezes possibilitou diálogo entre demolidor e compradores, ampliando, assim, o conhecimento sobre a história da cidade e suas construções. Desta forma, foi evidenciado que o reaproveitamento e a reciclagem foram vantajosos do ponto de vista econômico, mas também e especialmente, simbólico e histórico. A partir do pressuposto de que todo espaço é uma construção social, e que os grupos produzem o espaço de acordo com sua visão de mundo, o grupo foi motivado a exercitar um estilo de vida voltado ao retorno à natureza, à estética nativa, à preservação do meio ambiente e à cultura do não consumismo. De acordo com a autora, são essas escolhas que incluem, excluem, definem e constroem grupos sociais.

Noutro assunto que extrapola fronteiras, o texto de Carla

Estamos diante de um

trabalho denso, profundo, muito informativo, que

recupera um debate sobre

assuntos cotidianos, e ao

mesmo tempo avança na

compreensão de dados

contemporâneos e futuros,

como a sustentabilidade.

Pires Vieira da Rocha faz abordagem ao consumo alimentar dos imigrantes transnacionais (que não somente brasileiros), vivendo na Holanda. Considerando que a qualidade de vida destes sujeitos é redimensionada a partir da emigração, a autora se utilizou dos parâmetros de estilo de vida, como sendo um conjunto mais ou menos integrado de práticas abraçadas por um indivíduo que, além de preencherem necessidade utilitárias, dão forma material a uma narrativa particular de autoidentidade, ou seja, aos seus projetos de vida. Ao avaliar as práticas alimentares de cunho ambiental destes, a autora demonstra que os interlocutores tiveram que fazer diversas adaptações tanto na aquisição, quanto no descarte. Na aquisição, a oferta de alimentos bio (aqueles cultivados de acordo com os preceitos ecológicos e comércio justo e local), embora muitas vezes têm custo mais baixo do que produtos convencionais, não estariam disponíveis a todos os bairros da cidade. No contraponto, alguns interlocutores denunciam a grande oferta de produtos importados e origens diversas, que sugerem a presença de muitos agrotóxicos. Já no descarte, os imigrantes relatam demasiadas embalagens que poderiam ser evitadas. Parece haver um declínio no interesse dos imigrantes ao correto descarte e separação de resíduos.

O potencial de reutilização de resíduos orgânicos é discutido por Schneider e Almeida a partir das diferentes concepções de classes sociais. As autoras explicam a teoria da ideia central da análise, fazendo uma distinção entre duas categorias de preferências (gostos), as quais sofrem influências do poder econômico e cultural, a saber: "[...] "gosto puro" [...]" (1) e "[...] "gosto bárbaro" [...]" (2) (p. 202). Visto que a ideia de lixo é algo relativizado, o foco foi diferenciar o que é considerado "[...] impróprio [...]" (p. 204) do que é considerado "[...] "bom para comer [...]" (p. 205), e como as diferentes classes lidam com essas concepções. A etnografia que embasa o texto foi pautada em dois eventos realizados em momentos e locais diferentes na cidade de Florianópolis (SC). Como conclusão dessa análise, o grupo 1 demonstrou fazer menos adequadamente o tratamento dos resíduos do que o grupo 2, capaz de reutilizar e promover meios menos impactantes ao meio ambiente.

Outrossim, fazendo parte do projeto procedente desta obra, está o capítulo de Nunes e Jahnecka, que fez uma descrição de narrativas etnográficas da vida sobre as águas urbanas a partir da pesquisa de campo, realizada no Rio Amstel (que originou o nome da cidade de Amsterdã) e em seus canais fluviais. As autoras relataram um grande contraste dessa relação, especialmente quando comparadas à população ribeirinha de 
arroios localizados no sul do Brasil. Desta forma, ficou evidente que há sim outras formas (e melhores) de se relacionar com águas urbanas.

A terceira parte do livro amplia o olhar para os Novos Resíduos Sólidos: e-waste e nuclear. Aqui os investigadores vão muito além do que já foi abordado, fornecendo ao leitor uma visão do todo (visão holística). A produção de resíduos é uma ação natural que está presente em todos os ecossistemas. Entretanto, o consumo elevado e globalizado de produtos de tecnologias da informação e comunicação (TIC) tem gerado um tipo de resíduo eletrônico, o qual tem uma relação diferenciada quando a questão é a sustentabilidade. A Sociedade da Informação e Comunicação e as consequências do consumo global de produtos de TIC foram elucidadas no texto escrito por João Alves de Lima e Julia Sílvia Guivant, motivados pela questão de quem é a responsabilidade da gestão do $e$-waste. Apresentam dados impressionantes em relação às quantidades (produzidas e descartadas) de $e$-waste e as rotas de movimentação de produtos perigosos até países como Gana e Índia, entre outros. São utilizadas como referências especialmente as definições de Sociedade de Risco (BECK, 2010 apud RIAL, 2016) e abordagem da Sociedade Contemporânea (GIDDENS, 2012 apud RIAL, 2016), polemizada pela ameaça globalizada da modernidade às questões ambientais. Nesse sentido, fica desmistificada a ideia de que a tecnologia é orientada por uma lógica autônoma e desvinculada do contexto social e por isso, essa responsabilidade deve ser encarada como uma ação coletiva. O Brasil, classificado como $5^{\circ}$ maior produtor, fica atrás da China, EUA, Japão e Rússia, um cenário comprometedor e desafiador ao mesmo tempo. Interessante é o fato de que, além da problematização, o capítulo também apresenta possíveis soluções, indicando modelos de reciclagem. Ademais, são atividades que podem representar alternativas de inclusão social e sociodigital. Redes de colaboração entre empresas privadas, organizações públicas e não governamentais têm desenvolvido ações para amenizar os impactos.

Enfim, o título desta coletânea nos permite vislumbrar que existem vários diálogos possíveis entre a antropologia e o tratamento dos RS (lixo), para além da reflexão do seu poder, muitas vezes invisível. Estamos diante de um trabalho denso, profundo, muito informativo, que recupera um debate sobre assuntos cotidianos, e ao mesmo tempo avança na compreensão de dados contemporâneos e futuros, como a sustentabilidade. Seguramente, algumas pessoas vivendo em meio urbano, somente poderiam se apropriar desse domínio, quando o sistema de recolhimento de RS falhar, provocando o caos, tal qual ocorrido entre os anos de 2007 e 2008, onde se formaram enormes montanhas de lixo nas ruas, provocada por forte crise no setor de recolhimento e retomada de um lixão, o que fez escolas, empresas e a cidade inteira paralisar em Nápoles, na Itália (DIAS; GUIMARÃES, SANTARÉM, 2009).

A presente obra coloca em um novo patamar, o entendimento daquilo que é considerado lixo, bem como o que é consumo. Com muita qualidade, objetifica valores e concepções, e isso é o que deveria orientar as ações de descarte, e deveria ser a preocupação crescente das sociedades de consumo. Ademais, oferece um rico panorama do assunto nos dois países. Sobretudo, por ser fruto de um projeto que aborda a modernidade e as diferentes noções de pureza, o foco do trabalho foi o conhecimento compartilhado, muito bem apresentado, na forma de coletânea de textos sequenciais de vários escritores. São as diversidades apontadas e a interdisciplinaridade dos autores que oferecem uma fascinante visão entremeada na realidade atual, possui caráter acima de tudo reflexivo, além do investigativo. Ao colocar em novo patamar a questão social dos heróis da reciclagem e das políticas mais efetivas de cuidados e controle dos RS no Brasil, sua leitura é interessante e altamente recomendada a todos profissionais e estudantes preocupados com o meio ambiente e o enigma social do lixo.

\section{Referências}

DIAS, L. S.; GUIMARÃES, R. B.; SANTARÉM, V. Á. Observação da flutuação diária de dípteros muscóides, de importância para a saúde pública, no lixão de Presidente Prudente, São Paulo, Brasil. In: SIMPÓSIO NACIONAL DE GEOGRAFIA DA SAÚDE, 4., 2009, Uberlândia. Anais [...]. Uberlândia: Universidade Federal de Uberlândia, 2009. p. 2048-2062.

RIAL, C. (org.). O poder do lixo: abordagens antropológicas dos resíduos sólidos. Rio de Janeiro: Associação Brasileira de Antropologia, 2016.

\section{Notas}

1 É resultado de um convênio entre a Coordenação de Aperfeiçoamento de Pessoal de Nível Superior (CAPES) e a Nuffic, envolvendo equipes de pesquisadores da Universidade Federal de Santa Catarina (Brasil) e da University of Amsterdam (Holanda) com o projeto Modernidade, o meio ambiente e novas noções sobre lixo e pureza. Publicado pela ABA Publicações, encontra-se disponível gratuitamente em http:// www.portal.abant.org.br/publicacoes2/livros/OPoderDoLixoAbordagensAntropologicasDosResiduosSolidos.pdf. 
2 Reflete a desigualdade social e condições críticas de pobreza e saneamento absurdas, causadas pela urbanização e a comunidade aglomerada nos entornos do aterro do lixão Jardim Gramacho (RJ): já foi o maior do mundo em volume, (9,5 mil t./dia de resíduos), jogados a céu aberto onde era disputado por urubus e por 1.800 pessoas. Os catadores retiravam $200 \mathrm{t}$./dia de materiais recicláveis, o que apontou a falta de comprometimento da população e do governo quanto à coleta seletiva. Enfim, em 2012, este aterro foi desativado, após 30 anos de funcionamento e destruição.

3 Autoconstrução foi especificada como uma forma específica de estruturação do espaço doméstico, um modo de expressão e participação dos indivíduos num sistema de relações simbólicas e significativas, portanto uma cultura.

\section{Claudia Ambrosi}

ambrosic@gmail.com

Mestrado em Nutrição, Metabolismo e Dietética pela Universidade Federal de Santa Catarina (UFSC)

Doutoranda no Programa de Pós-Graduação Interdisciplinar em Ciências Humanas da Universidade Federal de Santa Catarina (UFSC)

\section{UFSC}

Programa de Pós-Graduação Interdisciplinar em Ciências Humanas

Campus Universitário Reitor João David Ferreira Lima, Centro de Filosofia e Ciências Humanas, anexo do Bloco E, $2^{\circ}$ andar - Trindade

Florianópolis - Santa Catarina - Brasil

CEP: 88.040-900

\section{Agradecimentos}

Agradeço especialmente a Carmen Rial e Carla Pires Vieira da Rocha, pelo apoio e incentivo.

\section{Agência financiadora}

Bolsa de doutorado da Coordenação de Aperfeiçoamento de Pessoal de Nível Superior (CAPES). Processo: 1784446

Período de vigência: 01/03/2018 a 01/04/2021

Contribuições dos autores

Não se aplica.
Aprovação por Comitê de Ética e consentimento para participação

Não se aplica.

Consentimento para publicação

Não se aplica.

Conflito de interesses

Não há conflito de interesses. 